\title{
Onset of Afebrile Seizure in Transient Erythroblastopenia of Childhood
}

Toru Watanabe ${ }^{\star}$, Maho Nagasawa, Tomoka Matsuda, Kenichi Kinjyo, Ryoichi Kitagata, Keiko Hirano, Masami Shirai, Akira Endoh, Teruaki Hongo

Department of Pediatrics, Iwata City Hospital, 512-3, Iwata City, Shizuoka, 438-8550, Japan

\begin{abstract}
We describe a girl aged 2 years 2 months who presented with anemia and transient erythroblastopenia of childhood with the onset of afebrile seizure. She recovered spontaneously from transient erythroblastopenia of childhood 1 month after diagnosis without the need of any packed red cell transfusions. Although not a common disease, it was not very difficult to distinguish transient erythroblastopenia of childhood from other causes of anemia by patient history, physical examination, and limited blood testing. To our knowledge, this is one of the few documented cases of transient erythroblastopenia of childhood with neurological symptoms. Pediatricians should be aware of this disease to avoid unnecessary diagnostic procedures and treatment.
\end{abstract}

\begin{abstract}
Introduction
Transient erythroblastopenia of childhood (TEC) is a self-limited anemia and a disorder of young children (i.e., 3 months to 4 years) characterized by anemia associated with reticulocytopenia. That is a very rare disease. TEC occurs in previously healthy children and is secondary to temporary cessation of erythrocyte production. It is important to distinguish TEC from other causes of anemia, such as Diamond-Blackfan anemia (DBA). We report a girl, 2 years and 2 months old, with TEC associated with the onset of afebrile seizure. She did not develop anemia and reticulocytopenia and TEC resolved within 4 weeks. Afebrile seizure disappeared without sequelae. Afebrile seizure as a complication of TEC is rare and therefore, we report this case along with references to previous studies.
\end{abstract}

\section{Case Presentation}

A girl aged 2 years and 2 months was admitted with the complaint of afebrile seizure. We did not observe anything during the review of her family history. Furthermore, episodes were absent during her perinatal period. According to the patient's past history, she had a few breath-holding spells (BHS) 1 month before her admission.

The patient presented with a clonic seizure of the right hand for 1 minute on the day of admission. The following were observed during her examination at our hospital: heart rate of $97 / \mathrm{min}$ with a regular beat; blood pressure, $105 / 53 \mathrm{mmHg}$; respiratory rate, $20 / \mathrm{min}$; $\mathrm{SpO}_{2}$, $100 \%$ (room air); and body temperature, $37.4^{\circ} \mathrm{C}$. Her height and body weight was $80 \mathrm{~cm}(-1.7 \mathrm{SD})$ and $10 \mathrm{~kg}(-1.0 \mathrm{SD})$, respectively. Her consciousness was clear without any neurological symptoms. There were no remarkable chest, abdominal, or other findings except she had a pale colored face. The patient's hematological workup revealed moderate anemia. The following were observed in the complete blood count: white blood cell, $8800 / \mu \mathrm{L}$; neutrophils, $61 \%$; hemoglobin level, $6.5 \mathrm{~g} / \mathrm{dL}$; red blood cells, $241 \times 10^{4} / \mu \mathrm{L}$; low reticulocyte count $\left(7.23 \times 10^{3} / \mu \mathrm{L}\right)$; mean corpuscular volume, $83.8 \mathrm{fL}$; mean corpuscular hemoglobin, $27 \mathrm{pg}$; and mean corpuscular hemoglobin concentration, $32.2 \%$. According to these data, the patient was determined to have normocytic normochromic anemia and reticulocytopenia. The following laboratory findings were also noted: aspartate aminotransferase, $26 \mathrm{IU} / \mathrm{L}$; lactate dehydrogenase, $206 \mathrm{IU} / \mathrm{L}$; total bilirubin, $0.3 \mathrm{mg} / \mathrm{dL}$; serum iron, $119 \mu \mathrm{g} / \mathrm{dL}$; unsaturated iron binding capacity, $163 \mu \mathrm{g} / \mathrm{dL}$; and ferritin, $99 \mathrm{ng} / \mathrm{mL}$. She had low serum IgG $(572 \mathrm{mg} / \mathrm{dL})$ and high erythropoietin (EPO) $(563 \mathrm{mIU} / \mathrm{mL})$ levels (Figure1). The presence of coagulation disorders was not observed in the laboratory findings (Table 1).
The serum anti-human parvovirus B19 antibody was negative. Three days after her admission (day 3), her hemoglobin level decreased to $6.0 \mathrm{~g} / \mathrm{dL}$ without clear hemolysis or bleeding by ultrasonography. Her general condition was good and therefore, we did not perform a transfusion. The electroencephalogram (EEG) had broad asynchronous high voltage slow waves (Figure 2). A high intensity area was detected on the bilateral white matters around the cerebral ventricle using fluid attenuated inversion recovery and T2 weighted magnetic resonance imaging (MRI; Figure 3). Her hemoglobin levels spontaneously recovered to $6.5 \mathrm{~g} / \mathrm{dL}$ on day 8 without any treatment and to $7.7 \mathrm{~g} / \mathrm{dL}$ on day 11 with elevated reticulocytes, and she was discharged.

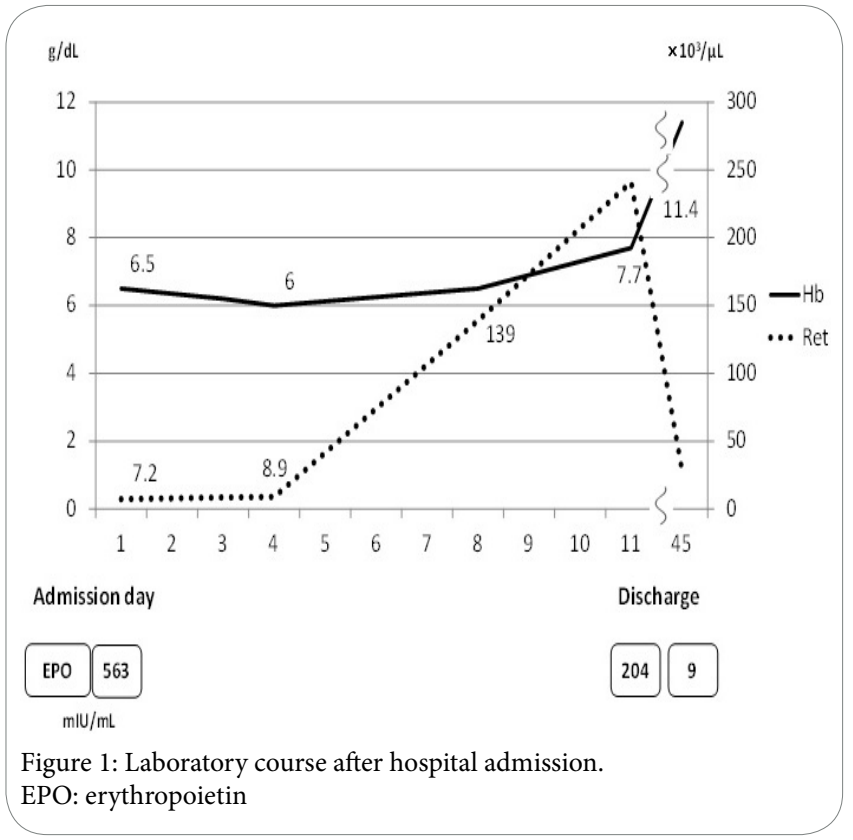

"Corresponding Author: Toru Watanabe, Department of Pediatrics, Iwata City Hospital, 512-3, Iwata City, Shizuoka, 438-8550, Japan, Tel: +81-538-38-5000; Fax: +81-538-38-5052; E-mail: brightsirius@msn.com

Citation: Watanabe T, Nagasawa M,Matsuda T, Kinjyo K, Kitagata R, et al. (2015) Onset of Afebrile Seizure in Transient Erythroblastopenia of Childhood. Int J Pediatr Neonat Care 1: 102. doi: http://dx.doi.org/10.15344/2455-2364/2015/102

Copyright: (c) 2015 Watanabe et al. This is an open-access article distributed under the terms of the Creative Commons Attribution License, which permits unrestricted use, distribution, and reproduction in any medium, provided the original author and source are credited. 
Citation: Watanabe T, Nagasawa M,Matsuda T, Kinjyo K, Kitagata R, et al. (2015) Onset of Afebrile Seizure in Transient Erythroblastopenia of Childhood. Int J Pediatr Neonat Care 1: 102. doi: http://dx.doi.org/10.15344/ijpnc/2015/102

\begin{tabular}{|c|c|c|c|}
\hline \multicolumn{2}{|c|}{ Complete blood count } & \multicolumn{2}{|l|}{ Biochemistry } \\
\hline WBC & $8800 / \mu \mathrm{L}$ & T.Bil & $0.3 \mathrm{mg} / \mathrm{dL}$ \\
\hline Neutrophils & $61 \%$ & Alb & $4.4 \mathrm{~g} / \mathrm{dL}$ \\
\hline Lymphocytes & $30 \%$ & AST & $26 \mathrm{IU} / \mathrm{L}$ \\
\hline $\mathrm{RBC}$ & $241 \mathrm{X} 104 / \mu \mathrm{L}$ & ALT & $11 \mathrm{IU} / \mathrm{L}$ \\
\hline $\mathrm{Hb}$ & $6.5 \mathrm{~g} / \mathrm{dL}$ & LDH & $206 \mathrm{IU} / \mathrm{L}$ \\
\hline $\mathrm{Ht}$ & $20.2 \%$ & BUN & $7 \mathrm{mg} / \mathrm{dL}$ \\
\hline $\mathrm{MCV}$ & $83.8 \mathrm{fL}$ & $\mathrm{Cr}$ & $0.22 \mathrm{mg} / \mathrm{dL}$ \\
\hline $\mathrm{MCH}$ & $27 \mathrm{pg}$ & $\mathrm{Na}$ & $136 \mathrm{mEq} / \mathrm{L}$ \\
\hline MCHC & $32.2 \%$ & $\mathrm{~K}$ & $4.4 \mathrm{mEq} / \mathrm{L}$ \\
\hline Reticulocytes & $0.3 \%$ & $\mathrm{Cl}$ & $103 \mathrm{mEq} / \mathrm{L}$ \\
\hline WBC & $8800 / \mu \mathrm{L}$ & $\mathrm{Ca}$ & $9.0 \mathrm{mg} / \mathrm{dL}$ \\
\hline \multicolumn{2}{|c|}{ Coagulation test } & $\mathrm{P}$ & $4.6 \mathrm{mg} / \mathrm{dL}$ \\
\hline $\mathrm{PT}$ & $11.6 \mathrm{~S}$ & CRP & $0 \mathrm{mg} / \mathrm{dL}$ \\
\hline APTT & $21.3 \mathrm{~S}$ & Glucose & $93 \mathrm{mg} / \mathrm{dL}$ \\
\hline D-dimer & $0.3 \mu \mathrm{g} / \mathrm{mL}$ & $\operatorname{IgG}$ & $572 \mathrm{mg} / \mathrm{dL}$ \\
\hline AT-3 & $106.4 \%$ & EBV/VCA/IgG & $0.1(<0.5)$ \\
\hline \multicolumn{2}{|l|}{ CSF analysis } & EBV/VCA/IgM & $0.2(<0.5)$ \\
\hline SG & 1.006 & EBV EBNA & $<10$ \\
\hline Protein & $22.9 \mathrm{mg} / \mathrm{dL}$ & Iron & $119 \mu \mathrm{g} / \mathrm{dL}$ \\
\hline Glucose & $79 \mathrm{mg} / \mathrm{dL}$ & UIBC & $163 \mu \mathrm{g} / \mathrm{dL}$ \\
\hline \multirow[t]{6}{*}{ Cell } & $0 / \mu \mathrm{L}$ & Ferritin & $99 \mathrm{ng} / \mathrm{mL}$ \\
\hline & & EPO & $563 \mathrm{mIU} / \mathrm{mL}$ \\
\hline & & Vitamin B12 & $203 \mathrm{pg} / \mathrm{mL}$ \\
\hline & & Folic acid & $18 \mathrm{ng} / \mathrm{mL}$ \\
\hline & & HPV B19/IgM & $0.36(<0.8)$ \\
\hline & & $\mathrm{HbF}$ & $1.7 \%$ \\
\hline
\end{tabular}

Table 1: Laboratory findings at hospital admission.

MCV: mean corpuscular volume; MCH: mean corpuscular hemoglobin; MCHC: mean corpuscular hemoglobin concentration; PT: prothrombin time; APTT: activated partial thromboplastin time; AT: antithrombin; EBV: Epstein-Barr virus; VCA: viral capsid antigen; EBNA: Epstein-Barr virus nuclear antigen; UIBC: unsaturated iron binding capacity; EPO erythropoietin; HPV: human parvovirus; HbF: hemoglobin F; CSF: cerebrospinal fluid; SG: specific gravity

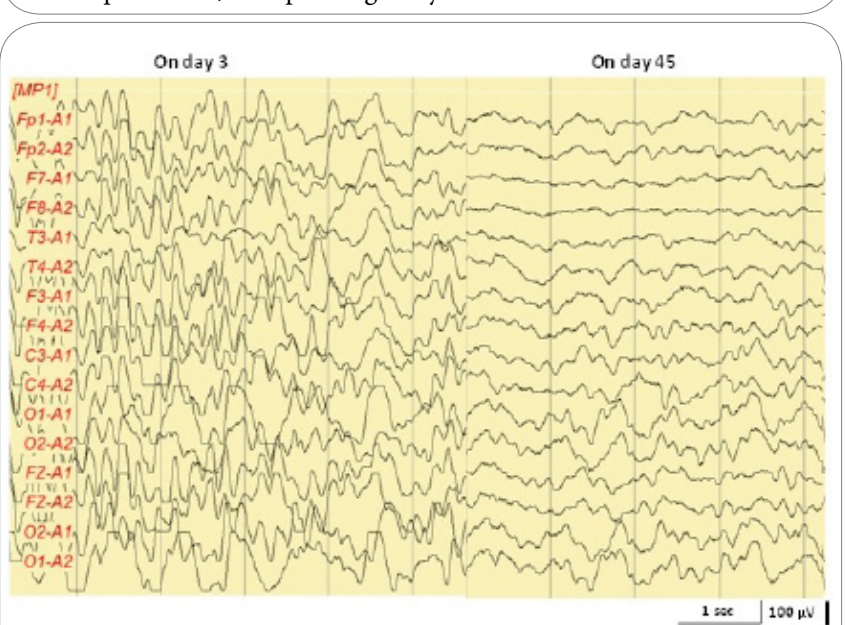

Figure 2. Electroencephalogram. Broad asynchronous high voltage slow waves are observed on day 3 . These slow waves improved on day 45 .

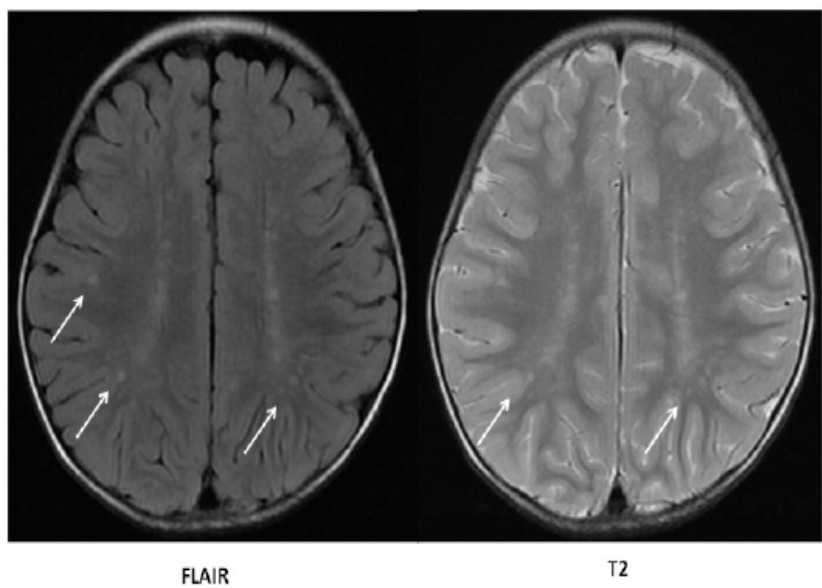

Figure 3: Fluid attenuated inversion recovery (FLAIR) and T2 weighted magnetic resonance imaging. High intensity areas on multiple white matters around the cerebral ventricles (white arrows) are shown in both FLAIR and T2 weighted images.

On day 45 , her hemoglobin level increased to $11.4 \mathrm{~g} / \mathrm{dL}$ with a normal reticulocyte count $\left(28.1 \times 10^{3} / \mu \mathrm{l}\right)$. The IgG level increased to $707 \mathrm{mg} / \mathrm{dL}$. Her EEG became almost normal with the disappearance of slow waves; however, the white matter lesions of the MRI remained. We did not perform a bone marrow puncture because her hemoglobin spontaneously returned to normal levels within 1 month assessing her clinical course and data. We diagnosed her with TEC based on the low reticulocytes in the acute phase, transient anemia, age, and clinical course. The gene mutations involved in the development of DBA (RPS7, RPS10, RPS19, RPS24, RPS26, RPL5, RPL26, RPL11, RPL35A, and GATA1) were not detected. She was immunocompetent and the anemia has not recurred to date.

\section{Discussion}

TEC is an uncommon, benign normocytic anemia of unknown cause characterized by reduced or absent mature erythroid precursors, in an otherwise normocellular bone marrow, and a complete spontaneous recovery. Although an association with viral infections has been proposed (some viral infection may induce a transient inhibition of erythroid cell formation) [1], the etiology of TEC remains unknown. TEC is usually observed in patients older than 6 months (generally between 1 and 4 years; range, 1 month to 6 years). Patients generally have anemia with hemoglobin levels of 6-8 $\mathrm{g} / \mathrm{dL}$ with reticulocytopenia. According to epidemiological data [2], the median age was 19 months, $56 \%$ children. At initial presentation, the median hemoglobin level was $4.4 \mathrm{~g} / \mathrm{dL}$, which indicated severe anemia. TEC is rarely experienced in practical clinics. Furthermore, TEC is now diagnosed less frequently than the last 2 decades. The treatment for TEC is supportive and sometimes transfusion is needed in severe cases. In our patient, clinical intervention was not required due to spontaneous recovery. Although the onset age of DBA is different from that of TEC and DBA has to be included in the differential diagnosis of TEC, the onset of TEC may be difficult to distinguish from DBA. TEC can be distinguished from DBA based on the above clinical and laboratory data. Unlike many patients with DBA, those with TEC are clinically normal. We could obviate a bone marrow aspiration by assessing these data. Pediatricians need to be aware of TEC in order to prevent unnecessary diagnostic and therapeutic measurements. 
Citation: Watanabe T, Nagasawa M,Matsuda T, Kinjyo K, Kitagata R, et al. (2015) Onset of Afebrile Seizure in Transient Erythroblastopenia of Childhood. Int J Pediatr Neonat Care 1: 102. doi: http://dx.doi.org/10.15344/ijpnc/2015/102

Page 3 of 3

In our present case, the anemia associated with TEC might have caused the afebrile seizure although severe anemia is not usually considered to be a cause of seizure. Anemia may lead to decreased oxygen uptake in the lungs and therefore, reduce oxygen available to the tissues, including central nervous system tissue. Anemia may be associated with a variety of neurologic manifestations and affect autonomic nervous function. Our patient showed the typical clinical course of TEC (i.e., anemia of 1-2 month duration with complete recovery). At the time of presentation, our patient might have already been in the recovery phase because her EPO level was very high $\mathrm{HbF}(1.7 \%)$ was also slightly high, which indicated fetus-like blood formation in the presence of high EPO. The patient's hemoglobin level was inversely correlated with EPO. In this case, EPO, rather than the erythrocyte level, served as an early marker of RBC production. A coincidence of hypogammaglobulinemia was also observed in a report regarding a case of TEC [3].

In the acute phase, transient low IgG might show transient bone marrow suppression. TEC was induced by the mechanism of bone marrow suppression by some trigger, which might lead to neurologic abnormalities of BHS and seizure. Chan et al. reported a case of TEC with transient neurologic deficit where the child's hemiparesis resolved within 24 hours after the appearance of the symptom [4]. Tam et al. reported a child with TEC involving BHS. This child was treated by oral iron supplementation, which resolved the spells but the anemia remained [5]. In our case, the serum iron and ferritin levels were normal and therefore, we did not provide her oral iron supplementation.

Iron deficiency anemia (IDA) is highly associated with BHS, and therefore, an evaluation of IDA with a complete blood count and serum ferritin levels is warranted in children with BHS [6]. In these reports, oral iron treatment was effective for $50 \%$ of BHS cases without IDA. The value of iron supplementation in children with BHS who are not anemic has not been well studied. However, the oral iron treatment can be considered for BHS until the improvement of clinical episodes even if patients do not have iron deficiency. The physiologic role of iron is to regulate the autonomic nervous system. Iron may still assist in the treatment of patients with BHS who are not anemic and have normal hemoglobin levels. According to previous data, the oxidative stress of serum was significantly higher in patients with BHS than in controls [7]. The pathophysiology of BHS is not fully understood and studies to elucidate this pathophysiology are anticipated.

The deterioration of the cerebral cortex as the suppression after the seizure was probably shown in the transient abnormal EEG. Simultaneously, high intensity areas on the white matter lesions were observed during MRI. This suggested the existence of hypoxia episodes and cerebral anoxia. Furthermore, the clonic movement of the limb might have possibly occurred as a result of this cerebral anoxia. All these findings spontaneously resolved with the improvement of anemia. Her seizure has not recurred to date.

\section{Conclusion}

We report a case of TEC associated with the onset of afebrile seizure. The existence of anemia and TEC must be considered during a case of seizure, which can prevent unnecessary diagnostic procedures.

\section{Conflicts of Interest}

The authors declare that there are no conflicts of interests.

\section{Acknowledgments}

We thank Dr. Etsuro Ito, Department of Pediatrics, Hirosaki University for analyzing the gene mutations.

\section{References}

1. Penchansky L, Jordan JA (1997) Transient erythroblastopenia of childhood associated with human herpesvirus type 6, variant B. Am J Clin Pathol 108: 127-32.

2. Van den Akker M, Dror Y, Odame I (2014) Transient erythroblastopenia of childhood is an underdiagnosed and self-limiting disease. Acta Paediatr 103: e288-294.

3. Itonaga N, Ohtomo T, Kashii Y, Yamauchi T, Momoi MY (2000) Case of transient erythroblastopenia of childhood with transient hypogammaglobulinemia. Pediatr Int 42: 164-166.

4. Chan GC, Kanwar VS, Wilimas J (1998) Transient erythroblastopenia of childhood associated with transient neurologic deficit: report of a case and review of the literature. J Paediatr Child Health 34: 299-301.

5. Tam DA, Rash FC (1997) Breath-holding spells in a patient with transient erythroblastopenia of childhood. J Pediatr 130: 651-653.

6. Boon R (2002) Does iron have a place in the management of breath holding spells? Arch Dis Child 87: 77-78

7. Calik M, Abuhandan M, Aycicek A, Taskin A, Selek S, Iscan A (2013) Increased oxidant status in children with breath-holding spells. Childs Nerv Syst 29: 1015-1019. 